\title{
Research ethics committees at work: the experience of one multi-location study
}

\author{
Alison E While King's College, London
}

\begin{abstract}
Objectives - To report the outcome of applications to 43 research ethics committees.

Setting - Four regional health authorities in England. Findings - The research ethics committees varied considerably in their practices. The time lapse until notification of the outcome of the approval ranged from just under one week to 23 weeks with a mean of $8 \cdot 6$ weeks. Four research ethics committees failed to notify the research team of an outcome of their request for approval.

Conclusion - A national research ethics committee is needed to review national and multi-location research studies in the light of the fragmented and variable practice of local research ethics committees.
\end{abstract}

\section{Background}

The Department of Health ${ }^{1}$ issued a memorandum which required every district health authority to establish a research ethics committee whose role according to Kennedy ${ }^{2}$ included reviewing all research projects in terms of ethical considerations. Prior to the Department of Health ${ }^{1}$ memorandum, Gilbert $e t a{ }^{\beta}$ had noted considerable diversity in the practice of research ethics committees, not only in their composition but also in the methods they employed. This finding was similar to that of a large postal survey conducted by Nicholson ${ }^{4}$ whose particular concern related to research involving children and a small survey of Wessex. ${ }^{5}$ Ginzler et $a l^{6}$ also found great variation in the practices of 23 research ethics committees with the time for the processing of applications ranging from three to 32 weeks with a mean of 11.5 weeks. A larger study of 241 research ethics committees ${ }^{7}$ found great differences in their composition and in the sub-sample of 28 committees, there appeared to be considerable variation in their methods of operation. For example, the poor representation of the lay perspective was particularly noted by Neuberger and had also been considered a serious shortcoming by

\section{Key words}

Research ethics committees.
Herxheimer ${ }^{8}$ who accused research ethics committees of only reviewing research from the perspective of the research, to the exclusion of the patient. Further, Neuberger ${ }^{9}$ has drawn attention to the reluctance of some research ethics committees to regard social research as an acceptable approach to inquiry. Indeed, Oakley ${ }^{10}$ has asserted that research ethics committees are unsympathetic to social research and may act "as 'censors of research'... when research methods, designs and topics do not seem to fit the standard medical format". ${ }^{10}$ Hemminki and Kojo-Austin ${ }^{11}$ have reported this as a particular problem for multidisciplinary research The difficulty of gaining ethical approval through number of research ethics committees simul taneously for multi-centred trials has also been extensively acknowledged ${ }^{31012}$ and was the subject of a British Medical fournal editorial. ${ }^{13}$

\section{Method}

The research project focused upon the needs and provisions for families caring for children who might be expected to die during childhood and was funded by the Department of Health. The study involved interviews with a small number of parents in each health authority in four selected regional authorities using a modified OPCS Disability Survey ${ }^{14}$ interview schedule. The parents recruited themselves to the study through advertisements in voluntary group newsletters and thus contacted the research team to initiate recruitment. Representatives of the statutory and voluntary sector care providers were also interviewed voluntarily in selected health authorities. A letter was written with guidance from an ethicist and sent to research ethics committees seeking their advice as to whether the study required formal ethical approval since no patients (in this case, children) would be interviewed and all the normal ethical safeguards would be adhered to. Interestingly, the original OPCS Disability Survey ${ }^{14}$ did not seek ethical approval. The letters were addressed to the individual who had been identified as the correspondent for the local research ethics committee through a telephone survey of the 43 district health authorities. As far as possible the 


\section{Ethics} committee

\section{A1}

A2

A3

A4

A5
A6

A7

A8

A9

A10

A11

A12

A13

A14

A 15

A16

A17 of outcome in days

11 copies of $\mathrm{EC}$ form, 11 information letters, 11 consent forms; 1 protocol and 2 letters. (Attendance at committee requested)

1 protocol and 2 letters. (No approval needed)

2 letters

12 copies of EC form, 12 information letters, 12 consent forms, 12 protocols and 2 letters.

100

$\mathrm{EC}$ forms had to be signed by local doctor of consultant status

1 protocol, 1 interview schedule, 1 information letter, 1 consent form and 2 letters

1 letter. (No full review required)

9 copies of EC form, 9 information letters, 9 consent forms, 9 protocols, 2 interview schedules and 2 letters. Attendance at EC requested

1 letter. (No approval needed)

1 letter. (No formal review required)

1 protocol, 1 information letter, 1 interview schedule and 2 letters

1 letter. (No aproval needed)

1 protocol, 1 information letter, 1 consent form and 2 letters

1 letter. (No approval needed)

1 letter. (No formal review required)

1 letter. (No formal review required; EC meeting held in 34 days but notification 66 days later)

8 copies of EC form, 8 information letters, 8 consent forms, 1 interview schedule and 4 letters

2 letters

100
9
93
65
91
41
87
22
32
63
65
77
6
30
100
161
No response

individual or his/her secretary was spoken to in order to confirm that the correct person had been identified, together with the address for correspondence. The mailing took place in two groups: Group A on 11 May 1993 and Group B on 26 May 1993.

\section{Findings}

The time lapse until notification of the outcome of the approval process together with the contents of the correspondence are set out in figures 1 and 2 . The time lapse until notification of the outcome of the approval ranged from just under one week to twenty-three weeks with a mean of 8.6 weeks (the non-response of A17, B21, B25 and B26 committees excluded). The outcome of the original letter to the research ethics committees varied considerably, with some committees stating that no approval was needed while others required formal applications to be made either through completion of a specified form or through formal correspondence which included a research proposal and other requeste material and information. The cost of the approval process in terms of paper and photocopying therefore ranged from the cost of one letter to $£ 107.55$ for

Table 2 The outcome of group B mailing

\begin{tabular}{|c|c|c|}
\hline $\begin{array}{l}\text { Ethics } \\
\text { committee }\end{array}$ & Contents of total mailings & $\begin{array}{l}\text { ime elapsing before notification } \\
\text { of outcome in days }\end{array}$ \\
\hline B1 & 1 letter & 43 \\
\hline B2 & $\begin{array}{l}12 \text { copies of EC form, } 12 \text { information letters, } 12 \text { consent forms; } 12 \text { protocols, } 12 \text { interview } \\
\text { schedules and } 3 \text { letters. (EC attendance requested) }\end{array}$ & 106 \\
\hline B3 & Interview schedule and 2 letters & 54 \\
\hline B4 & $\begin{array}{l}16 \text { copies of EC form, } 16 \text { information letters, } 16 \text { consent forms and } 3 \text { letters. Telephone } \\
\text { discussion in lieu of attendance at EC meeting }\end{array}$ & 63 \\
\hline B5 & $\begin{array}{l}15 \text { copies of EC form, } 15 \text { information letters, } 15 \text { consent forms, } 3 \text { protocols and } 2 \text { letters. } \\
\text { Named sponsor in health authority needed }\end{array}$ & 77 \\
\hline B6 & 1 letter & 35 \\
\hline B7 & 1 letter. Chairman's action. (Confirmation by EC after 48 days) & 16 \\
\hline B8 & 1 letter & 30 \\
\hline B9 & 1 letter & 33 \\
\hline B10 & 2 letters & 41 \\
\hline B11 & 1 letter & 36 \\
\hline B12 & 1 protocol and 2 letters & 43 \\
\hline B13 & 10 copies of $\mathrm{EC}$ form, 10 information letters, 10 consent forms, 10 protocols and 2 letters & 123 \\
\hline B14 & $\begin{array}{l}12 \text { copies of EC form, } 12 \text { information letters, } 12 \text { consent forms, } 1 \text { protocol, } 1 \text { interview schedule } \\
\text { and } 2 \text { letters }\end{array}$ & 37 \\
\hline B15 & 17 copies of EC foprm, 17 consent forms, 1 interview schedule and 2 letters & 104 \\
\hline B16 & $\begin{array}{l}16 \text { copies of EC form, } 16 \text { information letters, } 16 \text { consent forms, } 4 \text { protocols, } 1 \text { interview schedule } \\
\text { and } 2 \text { letters }\end{array}$ & ale \\
\hline B17 & 2 letters & 48 \\
\hline B18 & 1 letter & 50 \\
\hline B19 & 2 letters & 35 \\
\hline B20 & 1 letter & 13 \\
\hline B21 & 3 letters and 1 telephone call & No outcome notified \\
\hline B22 & 11 copies of EC form, 11 information letters, 11 consent forms and 4 letters & 118 \\
\hline B23 & 1 letter & 29 \\
\hline B24 & 8 copies of $\mathrm{EC}$ form, 1 protocol, 1 interview schedule and 2 letters & 51 \\
\hline B25 & 2 letters & No response \\
\hline B26 & 2 letters & No response \\
\hline
\end{tabular}


2,151 sheets of paper for B2 committee (this excluded the costs of typing, postage and packaging). Considerable time was expended completing various forms, since each form was different, and writing letters answering specific questions raised by the different committees. No outcome was notified regarding four applications despite confirmation that correspondence was addressed correctly. In the case of A17, B25 and B26 non-response to the initial letter was followed up by telephone call after 54 days to confirm the local research ethics committee chairman and his/her address and preferred arrangements for correspondence. A second letter was then posted, which included a copy of the original letter and requested an urgent response from the committee regarding the need for, and procedure for seeking, formal ethical approval. Committee B21 entered into considerable correspondence with the research team, which extended over 82 days, notification of the views of the research ethics committee was expected but failed to be received after a further 28 days. A telephone call was therefore made to the secretary of the committee, who assured the research team that the chairman would communicate the views of the committee in writing. No letter was ever received.

The idiosyncratic requirements of the different ethics committees was also noteworthy. For example, one research ethics committee required all ethics committee forms to be signed by a doctor of consultant status working within the health authority. Completion of this formal application was achieved through a medical colleague based in the researcher's institution persuading a paediatrician contact to be helpful. Another research ethics committee required the naming of a sponsor within the health authority and in this case a senior nurse was contacted and agreed to be named. Two research ethics committees required the naming of a local medical contact regarding the research project and a further two requested that the general practitioners of the families be contacted prior to recruitment to the study, despite the fact that parents initiated the contact with the research team. Three research ethics committees requested that the research team be available to attend their meetings, however, telephone availability was accepted in view of the geographical distances involved.

\section{Discussion}

The gaining of ethical approval for this study required considerable time and resources, neither of which were fully expected. Further, while special care needs to be exercised when undertaking research in sensitive areas such as childhood death, the research ethics committees were idiosyncratic in their practices and did not always appear to follow the published guidelines. ${ }^{115}$ In part this may have reflected differential resources allocated to sustaining the research ethics committees as well as workload demands of the committee members and historical precedent. None the less, it was clear that some of the research ethics committees were poorly managed, leaving the researchers unable to obtain their views. It is noteworthy, however, that substantial inconsistencies were found in the practice of ethics committees in the United States (Institutional Review Boards) even when presented with the same research proposal. ${ }^{16}$

While this study did not investigate ethics committee membership, Benson ${ }^{16}$ and Neuberger ${ }^{9}$ have noted the different memberships of ethics committees and in consequence the variability of their practices reflecting this. Further, Cartwright and Seale, ${ }^{17}$ Neuberger ${ }^{9}$ and Oakley ${ }^{10}$ have drawn attention to the particular difficulties faced by social research in gaining acceptance among research ethics committees. Cartwright and Seale ${ }^{17}$ reported enormous difficulties at the early stages of their study investigating the last year of people's lives: "Our experience with ethical committees shows that standards and criteria vary between committees. It has not given us any confidence in the system or led us to feel that committees necessarily make the decisions on either rational or ethical grounds". ${ }^{17}$ Similarly, Oakley ${ }^{18}$ documented the difficulties that she encountered in gaining ethical approval for the Social Support and Pregnancy Outcome Study and she cautioned that: "these committees ought to have paid more scrupulous and systematic attention to their business" although she conceded that her study benefited from "irregular means" in gaining ethical approval.

\section{Conclusion}

The maintenance of high ethical standards in research is clearly desirable and to this end the Royal College of Physicians ${ }^{15}$ and the Department of Health ${ }^{1}$ have published clear guidelines regarding the role of research ethics committees in the United Kingdom in monitoring research involving human subjects. However, while it is inevitable that there will be some diversity in the practice of research ethics committees, reflecting local needs, this study has identified a worrying variability in their practices. Indeed, the multi-location study researcher continues to face a confusing situation despite the introduction of guidelines ${ }^{115}$ and the subsequent King's Fund Report. ${ }^{9}$ The present system is fragmented and will potentially discourage worthwhile national and multi-location studies in view of the high costs of gaining approval and disrupted timetables caused by unpredictable delays. Requests for protocol amendments have also been reported which in some cases have led to considerable difficulties for multi-location studies. ${ }^{19}$ The adoption of a common application 
form may be a helpful adjunct, however, the variability of views espoused by different research ethics committees will continue to challenge the successful execution of national and multi-location studies. The case for the establishment of a national research ethics committee for the review of national and multi-location studies now needs urgent consideration.

\section{Acknowledgement}

This paper draws upon research funded by the Department of Health. Responsibility for the views expressed, issues of interpretation, questions of inclusion and omission, remain as always with the author and do not necessarily reflect the views of the Department of Health.

Alison $E$ While, BSc, MSc, PhD, RGN, RHV, CertEd, is Professor of Community Nursing, Department of Nursing Studies, King's College, London.

\section{References}

1 Dept of Health. Local ethics committees. H SG (19) 5. London: Dept of Health, 1991.

2 Kennedy I. Research ethics committees and the law. In: Foster CG, ed. Manual for research and ethics committees [3rd ed]. London: Centre of Medical Law and Ethics, King's College London, 1994.

3 Gilbert C, Fulford KWM, Parker C. Diversity in the practice of district ethics committees. British Medical fournal 1989; 299: 1437-9.

4 Nicholson RH, ed. Medical research on children: ethics, law and practice. Oxford: Oxford Medical Publications, 1986.
5 Nott PN, Steel EA. Scrutinising research ethics committees [letter]. British Medical fournal 1988; 297: 1333.

6 Ginzler M, Davies J, McPherson K, Black N. Ethics committees and health services research. Fournal of Public Health Medicine 1990; 12: 190-6.

7 Neuberger J. Ethics and health care: the role of research ethics committees in the United Kingdom. London: King's Fund Institute, 1992.

8 Herxheimer A. The rights of the patient in clinical research. Lancet 1988; 331: 1128-30.

9 Neuberger J. Research ethics committees. In: Harrison A, ed. Health care UK. London: King's Fund Institute, 1990: 24-31.

10 Oakley A. Social support and motherhood. Oxford: Blackwell, 1992: 130.

11 Hemminki E, Kojo-Austin H. Problems of multidisciplinary research in health care - the case of birth services. Acta Sociologica 1989: 32(2): 253-60.

12 Berry TJ, Ades TE, Peckham CS. Too many ethical committees [letter]. British Medical fournal 1990; 301: 1274

13 Local research ethics committees [editorial]. British Medical fournal 1995; 311: 639-40.

14 OPCS. The prevalence of disability among children. Surveys of disability in Great Britain. Report No 3. London: HMSO, 1989.

15 Royal College of Physicians. Guidelines on the practice of ethics committees in medical research involving human subjects. London: Royal College of Physicians, 1990.

16 Benson PR. The social control of human biomedical research: an overview and review of the literature. Sociab Science and Medicine 1989; 29(1): 1-12.

17 Cartwright A, Seale C. The natural history of a survey: at account of the methodological issues encountered in a stud of life before death. London: King Edward's HospitaT Fund, 1990: 38.

18 See reference 10: 129.

19 Hotopf M, Wessely S, Noah N. Are ethical committees reliable? Fournal of the Royal Society of Medicine 1995; 88: $31-3$.

\section{News and notes}

\section{Call for abstracts}

The 11 th annual conference of the European Society for Philosophy of Medicine and Health Care - theme: "Research in health care - philosophical, ethical and historical aspects" will be held from August 21-23, 1997, in Padova, Italy.

Please send abstracts ( $\max 500$ words as well on diskette in Word Perfect or Dos/Sc) before March 1, 1997 to Professor dr Henk ten Have, secretariat ESPMH, Dept of Ethics, Philosophy and History of Medicine, Faculty of Medical Sciences, Catholic University of Nijmegen, PO Box 9101, $6500 \mathrm{HB}$ Nijmegen, the Netherlands. Fax: 024-3540254, from abroad: ++31-24-3540254. 